$\xi=$

\title{
Exploration of In-vitro antimicrobial and cytotoxic potentials of crude methanolic extracts of Quisqualis indica (stem bark): An ethno medicinal plant
}

\author{
Meer Hossain ${ }^{2}$, Md. Saddam Hussain ${ }^{1 *}$, Moin-Ul-Islam ${ }^{2}$, Md. Abdur Rahman ${ }^{1}$, \\ Md. Shalahuddin Millat ${ }^{1}$, Mirza Nusrat Sweety ${ }^{2}$ \\ ${ }^{1}$ Department of pharmacy, Noakhali Science and Technology University, Sonapur-3814, Noakhali, Bangladesh \\ ${ }^{2}$ Department of Applied Chemistry and Chemical Engineering Noakhali Science and Technology University, Sonapur, Noakhali-3814 \\ *Corresponding author E-mail: shussain070591@gmail.com
}

\begin{abstract}
Quisqualis indica plant (Stem bark) was analyzed in-vitro to evaluate biological activities including anti-microbial properties and cytotoxic potentials. The crude n-hexane, carbon tetrachloride, chloroform and aqueous soluble partitionates of the methanolic extract of the plant were subjected to the microbiological investigation against a wide range of Gram positive, Gram negative bacteria and fungi. Brine shrimp lethality bioassay was used for evaluation of cytotoxic activity of Quisqualis indica. The zones of inhibition produced by the hexane, carbon tetrachloride, chloroform and aqueous soluble partitionates of the methanolic extract of Quisqualis indica were ranged from 7-15 mm, 8-18 mm, 12-20 mm and 10-16 mm respectively at a concentration of 400 $\mu \mathrm{g} / \mathrm{disc}$. The obtained results were compared against standard Kanamycin $(30 \mu \mathrm{g} / \mathrm{disc})$. In case of brine shrimp lethality bioassay, the $\mathrm{n}$-hexane, carbon tetrachloride, chloroform and aqueous soluble partitionates were found to show $\mathrm{LC}_{50}$ of $1.254,0.826,3.866$ and $5.366 \mu \mathrm{g} / \mathrm{ml}$ respectively as compared with vincristine sulfate (with $\mathrm{LC}_{50}$ value of $0.3229 \mu \mathrm{g} / \mathrm{ml}$ ) as a standard positive control. The obtained results confirmed the presence of anti-microbial properties and cytotoxic potentials of Quisqualis indica which supports the traditional use of this plant in various diseases caused by pathogenic microorganisms and can be a good candidate for a further anti-tumor drug study.
\end{abstract}

Keywords: Quisqualis Indica; Combretaceae; The Zone of Inhibition; Kanamycin; Brine Shrimp Lethality Bioassay; Vincristine Sulfate.

\section{Introduction}

Microorganism like bacteria, virus and fungi are responsible for various life-threatening infectious disease in both human and animals throughout the world and placing the remarkable position of causing death in developing countries (Khan, et al., 2007). Antimicrobials are those agents used to encounter the infection caused by these microbes and searching for new antimicrobial agents is greatly beneficial for the improvement of the quality of human health and wellbeing (Rahman, et al., 2014). But one of the common problem in using antimicrobial agents is the rapid emergence of resistance, which provides an extra burden to the clinicians and the pharmaceutical industries (Hossain, et al., 2014). In many third world countries like Bangladesh, Srilanka, Ghana, Sudan irrational use of antimicrobial agents is a prime cause of such drug resistance (Khan, et al., 2007). Besides this, most of our market available antimicrobial drugs possess remarkable side effects. So it is a continuous and urgent need to discover new antimicrobial compounds with diverse chemical structures and novel mechanisms of action with fewer adverse effect (Bauer, et al., 2003). Screening of natural products from medicinal plants can be a source of new antimicrobial agents for the researcher (Runyoro, et al., 2006; Shahidi, 2004).

Cancer or malignancy of tumor is a condition which is manifested by abnormal cellular growth, lack of control of the cell proliferation, differentiation and death usually may affect more or less than 200 different types of cell (de Mesquita, et al., 2009). One study reveal that, there are about 10 million of incidence of different types of carcinoma worldwide, most of which are in developed countries (Cozzi, et al., 2004). There are several means of treating cancer including surgery, radiation therapy and chemotherapy with the aim of eradicating all cancerous cell from the body (Kintzios and Barberaki, 2004), but each of the treatment procedure possess several difficulties like drug resistance, toxicity, and low specificity. Most of our currently used chemotherapeutics are synthetic which possess several drawbacks and thus the screening of novel chemotherapeutic agents from natural source especially from plants origin is expanding in recent years (Balunas and Kinghorn, 2005).

From the ancient time, human beings are greatly relying on nature for their any primary health complaints and nature is always a good source of medicine obtained from animal or plant i.e. nature. Plants which are capable of treating various types of disease designated as medicinal plants and almost $80 \%$ of world population directly or indirectly rely on herbal medicine for their primary health care needs (FAO, 2004). Plants are capable of producing primary metabolites, which include carbohydrates, protein, fat, and some additional compounds called secondary metabolites including alkaloid, tannin, flavonoid and phenolic compounds (Edeoga, 2005). Primary metabolites act as a component of food and beverage while the secondary metabolites protect the plants from the environmental hazard and possess antimicrobial, antioxidant, anticancer and apoptosis inducing properties (Clement et al., 1998), and are the primary source of pharmaceuticals (Rao and 
Ravishankar, 2002). Now in recent times, the screening of these plants is an urgent need, in order to validate their use in folk medicine and to reveal the active principle by isolation and characterization of their constituents (Ali et al., 2001).

Quisqualis indica is an evergreen plant belonging to the family "Combretaceae". It is a warmer climates creeping shrub that can reach as much as 70 feet in tropical climates. The plant is originated from Burma, Malay Peninsula, New Guinea, and the Philippine Islands (Welsh, 1998). In Bangladesh, this plant is locally known as "Madhabi Lata" and available in the deep forest of Hill Tracts of Chittagong (Mia, 2006). The whole plant contains medicinal value including fruits against a toothache, ascariasis, oxyuriasis, food stagnancy and infantile malnutrition (Beers and Berkow, 1999; Mercola, 2006; De Padua, et al., 1999) ; seeds against diarrhea, fever, rickets (De Padua, et al., 1999) ; leaves are useful in abdominal pain and ache, remedy for boils and ulcers (De Padua, et al., 1999) ); roots as a vermifuge, to treat rheumatism and diarrhea (De Padua, et al., 1999).

\section{Materials and method}

\subsection{Chemicals and reagents}

Carbon tetra chloride, chloroform, n-hexane and methanol were purchased from Sigma-Aldrich (India). Vincristine sulfate was purchased from Popular Pharmaceutical Ltd., Bangladesh. All other chemicals and reagents used were of analytical grade.

\subsection{Collection and preparation of the plant material}

Plant sample of Quisqualis indica was collected from Dhaka in August 2015 and was identified by Department of Botany, University of Dhaka. The bark of the stem was first separated by means of a sharp knife, pierces into small pieces and then air-dried for several days. Then the pieces were subjected to oven dry for 24 hours at low temperature possible to facilitate grinding process. It was then grounded into coarse powder.

\subsection{Extraction}

About $750 \mathrm{~g}$ air-dried and powdered plant materials were submerged with $300 \mathrm{ml}$ of $80 \%$ methanol in an air-tight flat bottomed container for a period of 15 days at room temperature and continue to shake and stirrer at regular interval of time. Then the slurry was first filtered through a clean white cotton material for coarse filtration and finally with a Whatman No.1 filter paper. The volume of the filtrate was then reduced using a Buchii Rotavapor at low temperature and pressure. The weight of the crude extract was $5.2 \mathrm{gm}$.

\subsection{Solvent - solvent partitioning}

Solvent-solvent partitioning was done using the protocol designed by Kupchan and modified by Van Wagenen et al. 1993. The crude extract (5 gm) was dissolved in $10 \%$ aqueous methanol. It was extracted with $\mathrm{n}$-hexane, then with carbon tetrachloride and finally with chloroform. All the four fractions were evaporated to dryness by using Rota Cool and then kept for further analysis in beakers.

\subsection{Anti-microbial activity}

Due to the rapid emergence of resistance to antimicrobial agents it is the prime concern of the researcher to find out new antimicrobial agent from a natural source. For this purpose, screening of antimicrobial agent from a natural source is important. Here we used standardized single-disk diffusion method with little bit modification for performing the antimicrobial susceptibility test. It is widely accepted in vitro investigation for preliminary screening of test agents described by Bayer et al., 1966 (Bayer et al., 1966).

\subsubsection{Test micro-organisms}

Here we used several strains of Gram-positive bacteria (Bacillus cereus, Bacillus megaterium, Bacillus subtilis, Staphylococcus aureus, Sarcina lutea), Gram negative bacteria (Escherichia coli, Pseudomonas aeruginosa, Salmonella paratyphi, Salmonella typhi, Shigella boydii, Shigella dysenteriae, Vibrio mimicus, Vibrio parahemolyticus) and fungi (Candida albicans, Aspergillus niger, Sacharomyces cerevaceae) as a test organism. The microbial strains used for the experiment were collected from pure cultures from the Department of Microbiology, Noakhali Science and Technology University, Sonapur-3814, Noakhali, Bangladesh.

\subsubsection{Preparation of medium}

To prepare fresh cultures and to test the sensitivity of the materials against micro-organism we used Nutrient agar medium (DIFCO). For preparing the media specified amount of nutrient agar was taken in a conical flask and distilled water was added to it to make the required volume of $1000 \mathrm{ml}$. For perfect dissolution, the contents were heated in a water bath with continuous steering and the $\mathrm{p}^{\mathrm{H}}$ (at $25^{\circ} \mathrm{C}$ ) was maintained at 7.2-7.6 using $\mathrm{NaOH}$ or $\mathrm{HCl}$. The tip of the flask was mounted with a flag of cotton and aluminum foil and subjected to sterilization by autoclaving machine at a pressure of $15 \mathrm{lbs} / \mathrm{sq}$ inch, for 25 minutes at $125^{\circ} \mathrm{C}$ temperature. About $10 \mathrm{ml}$ and $5 \mathrm{ml}$ of the medium was then transferred into screw cap test tubes to prepare plates and slants respectively and lower the temperature to $45-50^{\circ} \mathrm{C}$. The slants were used for making the fresh culture of microorganisms that were in turn used for sensitivity study.

\subsubsection{Sterilization procedures}

To protest any type of microbial contamination and crosscontamination by the test organism's whole procedure was done in Laminar Hood and all types of precautions were strictly maintained. Before working in the Laminar Hood UV light was switched prior an hour. Petri dishes and other glassware were sterilized by autoclaving at a temperature of $121^{\circ} \mathrm{C}$ and a pressure of 15 -lbs./sq.inch for 15 minutes. Micropipette tips, cotton, forceps, blank discs were also sterilized by autoclave.

\subsubsection{Subculture preparation}

Test organism was transferred into the agar slants from pure culture aseptically under laminar air flow cabinet by means of a transfer loop to have fresh pure cultures. It was then incubated at $37^{\circ} \mathrm{C}$ for 24 hours to allow optimum growth of the microorganism which was then used for a sensitivity test.

\subsubsection{Preparation of test plates}

After 24 hours of sub-culture preparation, test organisms were transferred into the test tubes containing about $10 \mathrm{ml}$ of melted and sterilized agar medium by the assist of a sterilized transfer loop in an aseptic area. It was then shaken by continuous rotation to obtain a uniform suspension of the organism and immediately transferred into sterilized Petri dishes. To assure homogenous distribution of the test organisms in the media the Petri dishes were rotated several times in clockwise and anticlockwise direction.

\subsubsection{Discs preparation}

For antimicrobial screening, we used three different types of disc namely standard, blank and sample disc. Standard disc was used as a positive control to test the response of standard antibiotic agents against test micro-organism plus a comparison of response given by the known antibacterial agent with that of produced by the test sample. Here we used Kanamycin $(30 \mu \mathrm{g} / \mathrm{disc})$ standard disc as the reference. Blank discs were used as negative control, which ensures that the residual solvents (left over the discs even 
after air-drying) \& the filter paper were not active themselves. For preparing the test sample, $10 \mathrm{mg}$ of dried crude extracts was dissolved in $10 \mathrm{ml}$ to make the concentration of $1 \mathrm{mg} / \mathrm{ml}$. Under the laminar hood sterilized metrical (BBL, Cockeysville, USA) filter paper discs were taken in a blank Petri dish and soaked with solutions of test samples and dried so that the final volume is 400 $\mu 1 /$ disc.

\subsubsection{Diffusion and incubation}

After that, sample, standard antibiotic and control discs were placed gently on the previously marked zones in the agar plates pre-inoculated with test microorganisms by using a sterile forceps. The discs were placed $15 \mathrm{~mm}$ far from the edge of the plates and from each other to avoid overlapping of the zone of inhibition The plates were then kept in a refrigerator at $4{ }^{\circ} \mathrm{C}$ for about 24 hours upside down to allow sufficient diffusion of the materials from the discs to the surrounding agar medium. The plates were then inverted and kept in an incubator at $37^{\circ} \mathrm{C}$ for 24 hours for optimal microbial growth.

\subsubsection{Determination of antimicrobial activity by the zone of inhibition}

The antimicrobial potency of the test agents is measured by their activity to prevent the growth of microbes surrounding the discs, which give a clear zone of inhibition. After incubation, the antimicrobial activity of the test materials was determined by measuring the diameter of the zones of inhibition in millimeter using Varner's Caliper.

\subsection{Brine shrimp lethality bioassay}

The evaluation of pharmacologically active substance from plant materials is a recognized method for the identification of a lead compound, which serve as a basis for the development of novel and safe medicinal agents, (Huang and Monroe, 1998). The invivo lethality in a simple zoologic organism can be used as a convenient monitor for screening and fractionation in the discovery and monitoring of bioactive natural products. Meyer et al., 1982 focused on Artemia salina Leach as a test organism and developed a protocol for Brine shrimp lethality bioassay to monitor cytotoxicity of a compound. The method is very popular because it is very easy to perform, time-cost consuming and low toxin amounts are sufficient to perform the test in the micro-well scale. In our current study, chloroform, carbon tetra-chloride, hexane \& an aqueous soluble fraction of the methanolic extract of Quisqualis indica were screened for their cytotoxicity using brine shrimp lethality test.

\subsubsection{Preparation of seawater}

This is the first step of cytotoxic screening. To prepare the sea water $38 \mathrm{gm}$ sea salt (pure $\mathrm{NaCl}$ ) was weighed, dissolved in one liter of distilled water adjusted to $\mathrm{p}^{\mathrm{H}}-8.5$ using $1 \mathrm{~N} \mathrm{NaOH}$ and was filtered off to get a clear solution.

\subsubsection{Hatching of brine shrimps}

About 10 gm of Artemia salina Leach (brine shrimp eggs) was collected from local pet shops previously prepared fresh artificial seawater was taken in the small tank and shrimp eggs were added to one side of the tank and then that side was covered. Under continuous air and light supply, the tank was allowed to constant aeration for $48 \mathrm{hrs}$ to hatch the shrimp and to be matured as nauplii. The matured nauplii were attracted to the lamp through the perforated dam and with the help of a Pasteur pipette 10 living nauplii were added to each of the test tubes containing $5 \mathrm{ml}$ of brine solution

\subsubsection{Preparation of test solutions}

The test solution was prepared by dissolving measured amount (2 $\mathrm{mg}$ ) of each sample in $60 \mu \mathrm{l}$ of DMSO. DMSO was used to prepare a series of solutions of lower concentrations by serial dilution method. About $30 \mu \mathrm{l}$ test solution from each type of sample was added to pre-marked glass vials/test tubes containing $5 \mathrm{ml}$ of seawater and 10 shrimp nauplii in order to obtain the final concentration of samples $200 \mu \mathrm{g} / \mathrm{ml}, 100 \mu \mathrm{g} / \mathrm{ml}, 50 \mu \mathrm{g} / \mathrm{ml}, 25 \mu \mathrm{g} / \mathrm{ml}, 12.5$ $\mu \mathrm{g} / \mathrm{ml}, \quad 6.25 \mu \mathrm{g} / \mathrm{ml}, 3.125 \mu \mathrm{g} / \mathrm{ml}, 1.5625 \mu \mathrm{g} / \mathrm{ml}, \quad 0.78125 \mu \mathrm{g} / \mathrm{ml}$ $\& 0.390625 \mu \mathrm{g} / \mathrm{ml}$ respectively for 10 dilutions.

\subsubsection{Preparation of controls}

Vincristine sulfate (VINCRIRST ®, Techno Drugs Ltd. Bangladesh) served as the positive control. About $0.2 \mathrm{mg}$ of vincristine sulphate was dissolved in DMSO to get an initial concentration of $20 \mu \mathrm{g} / \mathrm{ml}$ from which serial dilutions were made using DMSO to get final concentration of $10 \mu \mathrm{g} / \mathrm{ml}, 5 \mu \mathrm{g} / \mathrm{ml}, 2.5 \mu \mathrm{g} / \mathrm{ml}, 1.25$ $\mu \mathrm{g} / \mathrm{ml}, 0.625 \mu \mathrm{g} / \mathrm{ml}, 0.3125 \mu \mathrm{g} / \mathrm{ml}, 0.15625 \mu \mathrm{g} / \mathrm{ml}, 0.078125$ $\mu \mathrm{g} / \mathrm{ml}$ and $0.0390 \mu \mathrm{g} / \mathrm{ml}$ respectively. The positive control groups containing 10 living brine shrimp nauplii in $5 \mathrm{ml}$ simulated seawater received the positive control solutions. For preparing negative control, $30 \mu \mathrm{l}$ of DMSO was added to each of the pre-marked test tubes containing $5 \mathrm{ml}$ of simulated seawater and 10 shrimp nauplii. If the negative control showed a rapid rate of mortality, then it was considered to be invalid one and therefore conducted again. The test tubes (with shrimps) were then maintained at room temperature for $24 \mathrm{hrs}$ under the light for observing the survival rate.

\subsubsection{Counting of nauplii and analysis of data}

After 24 hours, the number of survived nauplii in each test tube were inspected by using a magnifying glass and percent $(\%)$ of mortality was calculated for each dilution. By using Microsoft Excel Worksheet, the concentration-mortality data were analyzed which usually showed the effectiveness or the concentrationmortality relationship of plant product expressed as a median lethal concentration (LC50) value. This represents the concentration of the chemical that produces death in half of the test subjects after a certain exposure period.

\subsection{Statistical analysis}

All the above assays were conducted in triplicate and repeated threes for consistency of results and statistical purpose. The data were expressed as Mean \pm SD and analyzed SPSS software of 10 version.

\section{Results}

\subsection{Antimicrobial screening}

The antimicrobial activities of Quisqualis indica were examined in the present study. The results are given in table- 1 . The zones of inhibition produced by the hexane, carbon tetrachloride, chloroform and aqueous soluble partitionates of the methanolic extract of Quisqualis indica were ranged from 7-15 mm, 8-18 mm, 12-20 $\mathrm{mm}$ and $10-16 \mathrm{~mm}$ respectively at a concentration of $400 \mu \mathrm{g} / \mathrm{disc}$. The chloroform partitionate of the methanolic extract showed the strongest activity against B. subtilis \& V. mimicus having the zone size $20 \mathrm{~mm}$ for each. The growth of $\mathrm{S}$. aureus $(16 \mathrm{~mm}), \mathrm{V}$. parahemolyticus $(16 \mathrm{~mm})$, B. cereus $(15 \mathrm{~mm})$, E. coli $(15 \mathrm{~mm}), \mathrm{S}$. typhi $(15 \mathrm{~mm})$, P. aeruginosa $(14 \mathrm{~mm})$ was also strongly inhibited. Moderate activity was found against $\mathrm{S}$. paratyphi $(13 \mathrm{~mm}), \mathrm{B}$. subtilis $(12 \mathrm{~mm})$, S. lutea $(12 \mathrm{~mm})$. Among the fungi, the C. albicans was strongly inhibited having zone size $15 \mathrm{~mm}$. The growth of A. niger \& S. cerevaceae were moderately inhibited.

At the same time, the carbon tetrachloride partitionate of the methanolic extract showed strongest activity against $\mathrm{S}$. typhi hav- 
ing zone of inhibition, $17 \mathrm{~mm}$. The growth of $\mathrm{V}$. parahemolyticus $(16 \mathrm{~mm})$, B. cereus $(15 \mathrm{~mm}), \mathrm{S}$. aureus $(15 \mathrm{~mm}), \mathrm{S}$. lutea $(15 \mathrm{~mm})$ \& B. subtilis $(14 \mathrm{~mm})$ were strongly inhibited. Moderate activity was found against E. coli $(12 \mathrm{~mm}), \mathrm{V}$. mimicus $(11 \mathrm{~mm}), \& \mathrm{P}$ aeruginosa $(11 \mathrm{~mm})$. In the case of fungi, the growth of $\mathrm{A}$. niger was strongly inhibited having zone size of $18 \mathrm{~mm}$. Two other tested fungi were also strongly inhibited having zone size of inhibition $14 \mathrm{~mm}$ for each.

The aqueous partitionate of the methanolic extract of Quisqualis indica showed moderate to strong activity against the tested microorganisms. The growth of $\mathrm{B}$. subtilis $(16 \mathrm{~mm})$ was strongly inhibited. It also showed strong activity against B. cereus (15 $\mathrm{mm})$, V. mimicus (15 mm), S. lutea (14 mm), S. typhi $(14 \mathrm{~mm})$, \& B. megaterium $(13 \mathrm{~mm})$. Moderate activity was found against $\mathrm{S}$. aureus $(12 \mathrm{~mm})$, E. coli $(12 \mathrm{~mm})$, \& S. typhi $(12 \mathrm{~mm})$. At the same time weak to moderate activity $(10-13 \mathrm{~mm})$ was found in tested fungi.

The hexane soluble partitionate of the methanolic extract strongly inhibited the growth of B. megaterium \& V. mimicus having zone size $15 \mathrm{~mm}$ for each. It showed moderate activity against $\mathrm{S}$. aureus $(12 \mathrm{~mm}), \& \mathrm{~V}$. parahemolyticus $(12 \mathrm{~mm})$. Among the tested fungi, the growth of A. niger $(14 \mathrm{~mm})$ was strongly inhibited.
Following the procedure of Meyer (Meyer et al., 1982) the lethality of n-hexane (HX), $\mathrm{CCl} 4$ (CT), $\mathrm{CHCl} 3$ (CF) and aqueous (AQ) soluble partitionates of the methanolic extract to brine shrimp were investigated in this study.

Table-2 gives the results of the brine shrimp lethality after 24 hours exposure to all the samples and the positive control, vincristine sulfate. The positive control, compared with the negative control (sea water) was lethal, giving significant mortality to the shrimp. For brime shrimp lethargy bioassay for determination of cytotoxic activity of Quisqualis indica lethal concentration LC50 of the test samples after $24 \mathrm{hrs}$ was obtained by a plot of percentage of the shrimps killed against the logarithm of the sample concentration (toxicant concentration) and the best-fit line was obtained from the curve data by means of regression analysis (Table $3 \& 4)$.

The degree of lethality was directly proportional to the concentration of the extract ranging from significant with the lowest concentration $(0.0390 \mu \mathrm{g} / \mathrm{ml})$ to highly significant with the highest concentration $(200 \mu \mathrm{g} / \mathrm{ml})$. Maximum mortalities took place at a concentration of $200 \mu \mathrm{g} / \mathrm{ml}$, whereas least mortalities were at $0.0390 \mu \mathrm{g} / \mathrm{ml}$ concentration. In other words, mortality increased gradually with the increase in the concentration of the test samples.

LC50 obtained from the best-fit line slope were 0.3229, 1.254, $0.826,3.866$ and $5.366 \mu \mathrm{g} / \mathrm{ml}$ (Fig.1-5) for Std, HX, CT, CF and AQ soluble partitionates respectively.

\subsection{Brine shrimp lethality bioassay}

Table 1: Antimicrobial Activity of Test Samples of Quisqualis Indica

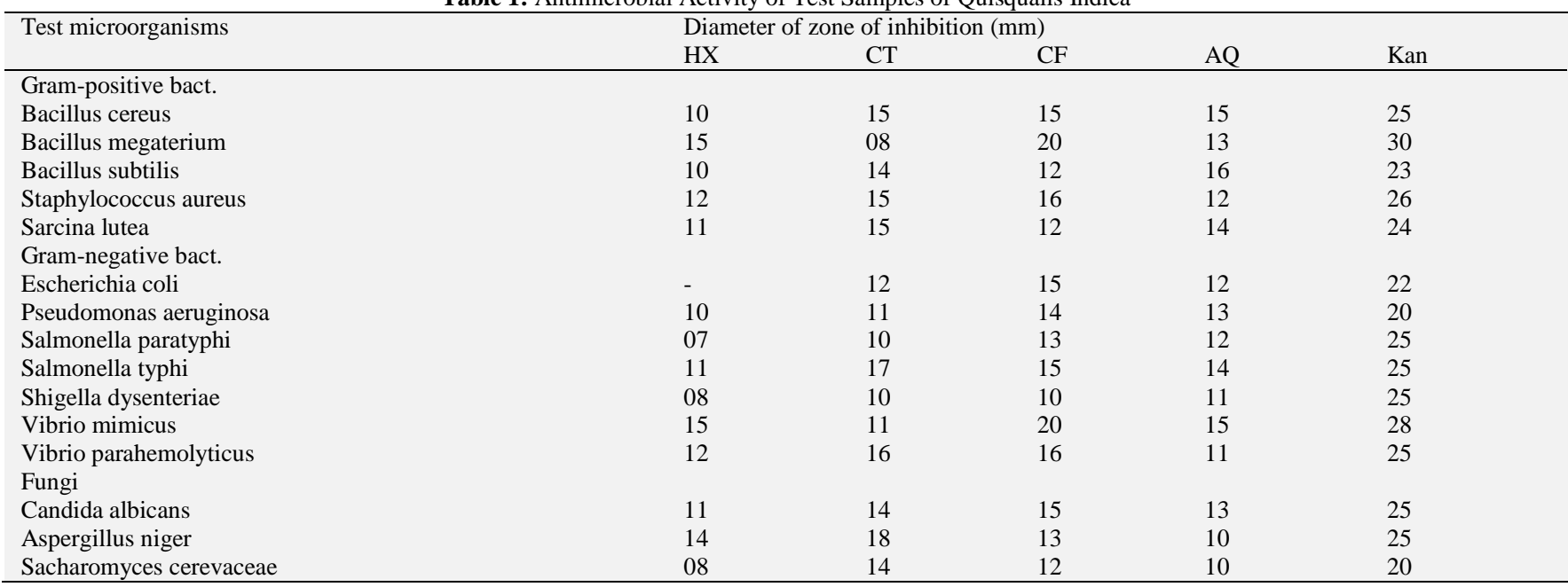

Here,

HX: Hexane fraction of the methanolic extract $(400 \mu \mathrm{g} / \mathrm{disc})$.

CT: Carbon tetrachloride fraction of the methanolic extract $(400 \mu \mathrm{g} / \mathrm{disc})$.

$\mathrm{CF}$ : Chloroform fraction of the methanolic extract $(400 \mu \mathrm{g} / \mathrm{disc})$.

AQ: Aqueous fraction of the methanolic extract ( $400 \mu \mathrm{g} / \mathrm{disc})$.

Kan: Kanamycin (Standard-30 $\mu \mathrm{g} /$ disc).

Table 2: Table: Brine Shrimp Lethality Bioassay Results of Quisqualis Indica

\begin{tabular}{|c|c|c|c|}
\hline Sample & $\mathrm{LC}_{50}(\mu \mathrm{g} / \mathrm{ml})$ & Regression equation & $\mathrm{R}^{2}$ \\
\hline Vincristine sulphate (Std.) & 0.3229 & $y=29.797 x+64.628$ & 0.927 \\
\hline HX & 1.254 & $y=24.763 x+47.564$ & 0.9775 \\
\hline $\mathrm{CT}$ & 0.826 & $y=22.348 x+51.85$ & 0.980 \\
\hline $\mathrm{AQ}$ & 5.366 & $y=27.381 x+30.087$ & 0.8441 \\
\hline
\end{tabular}

Here,

HX: Hexane fraction of the methanolic extract $(400 \mu \mathrm{g} / \mathrm{disc})$.

CT: Carbon tetrachloride fraction of the methanolic extract $(400 \mu \mathrm{g} / \mathrm{disc})$.

$\mathrm{CF}$ : Chloroform fraction of the methanolic extract $(400 \mu \mathrm{g} / \mathrm{disc})$.

AQ: Aqueous fraction of the methanolic extract ( $400 \mu \mathrm{g} / \mathrm{disc})$. 
Table 3: Effect of Hexane (HX) and Carbon Tetrachloride (CT) Soluble Partitionates of Methanolic Extract on Brine Shrimp Nauplii

\begin{tabular}{|c|c|c|c|c|c|c|c|c|c|}
\hline \multirow{2}{*}{$\begin{array}{l}\text { Conc. } \\
(\mu \mathrm{g} / \mathrm{ml})\end{array}$} & \multirow[b]{2}{*}{$\log C$} & \multicolumn{2}{|c|}{$\%$ Mortality } & \multicolumn{2}{|c|}{$\mathrm{LC}_{50}(\mu \mathrm{g} / \mathrm{ml})$} & \multicolumn{3}{|c|}{ Vincristine Sulphate } & \multirow[b]{2}{*}{$\begin{array}{l}\mathrm{LC}_{50} \\
(\mu \mathrm{g} / \mathrm{ml})\end{array}$} \\
\hline & & $\mathrm{HX}$ & $\mathrm{CT}$ & $\begin{array}{l}\text { HX } \\
\text { HX }\end{array}$ & CT & $\begin{array}{l}\text { Conc. } \\
(\mu \mathrm{g} / \mathrm{ml})\end{array}$ & $\log C$ & $\%$ Mortality & \\
\hline 200 & 2.301 & 100 & 100 & \multirow{10}{*}{1.254} & \multirow{10}{*}{0.826} & 40 & 1.602 & 100 & \multirow{10}{*}{0.3229} \\
\hline 100 & 2 & 100 & 100 & & & 20 & 1.301 & 100 & \\
\hline 50 & 1.699 & 90 & 90 & & & 10 & 1.000 & 100 & \\
\hline 25 & 1.398 & 80 & 80 & & & 5 & 0.698 & 90 & \\
\hline 12.5 & 1.097 & 80 & 80 & & & 2.5 & 0.397 & 80 & \\
\hline 6.25 & 0.796 & 70 & 70 & & & 1.25 & 0.096 & 80 & \\
\hline 3.125 & 0.495 & 60 & 60 & & & 0.625 & -0.204 & 60 & \\
\hline 1.563 & 0.194 & 50 & 60 & & & 0.3125 & -0.505 & 50 & \\
\hline 0.781 & -0.107 & 40 & 50 & & & 0.15625 & -0.806 & 40 & \\
\hline 0.390 & -0.468 & 40 & 40 & & & 0.078125 & -1.107 & 20 & \\
\hline
\end{tabular}

Table 4: Effect of Chloroform (CF) and Aqueous (AQ) Soluble Partitionates on Brine Shrimp Nauplii

\begin{tabular}{|c|c|c|c|c|c|c|c|c|c|}
\hline \multirow{3}{*}{$\begin{array}{l}\text { Conc. } \\
(\mu \mathrm{g} / \mathrm{ml})\end{array}$} & \multirow{3}{*}{$\log C$} & \multirow{2}{*}{\multicolumn{2}{|c|}{$\%$ Mortality }} & \multirow{2}{*}{\multicolumn{2}{|c|}{$\mathrm{LC}_{50}(\mu \mathrm{g} / \mathrm{ml})$}} & \multicolumn{3}{|c|}{ Vincristine Sulphate } & \multirow{3}{*}{$\begin{array}{l}\mathrm{LC}_{50} \\
(\mu \mathrm{g} / \mathrm{ml})\end{array}$} \\
\hline & & & & & & Conc. & $\log C$ & of Mortolity & \\
\hline & & $\mathrm{CF}$ & $\mathrm{AQ}$ & $\mathrm{CF}$ & $\mathrm{AQ}$ & $(\mu \mathrm{g} / \mathrm{ml})$ & $\log C$ & \% iviortally & \\
\hline 200 & 2.301 & 100 & 100 & \multirow{10}{*}{3.866} & \multirow{10}{*}{5.366} & 40 & 1.602 & 100 & \multirow{10}{*}{0.3229} \\
\hline 100 & 2 & 100 & 100 & & & 20 & 1.301 & 100 & \\
\hline 50 & 1.699 & 90 & 80 & & & 10 & 1.000 & 100 & \\
\hline 25 & 1.398 & 80 & 50 & & & 5 & 0.698 & 90 & \\
\hline 12.5 & 1.097 & 80 & 50 & & & 2.5 & 0.397 & 80 & \\
\hline 6.25 & 0.796 & 50 & 40 & & & 1.25 & 0.096 & 80 & \\
\hline 3.125 & 0.495 & 40 & 40 & & & 0.625 & -0.204 & 60 & \\
\hline 1.563 & 0.194 & 30 & 40 & & & 0.3125 & -0.505 & 50 & \\
\hline 0.781 & -0.107 & 30 & 30 & & & 0.15625 & -0.806 & 40 & \\
\hline 0.390 & -0.468 & 20 & 30 & & & 0.078125 & -1.107 & 20 & \\
\hline
\end{tabular}

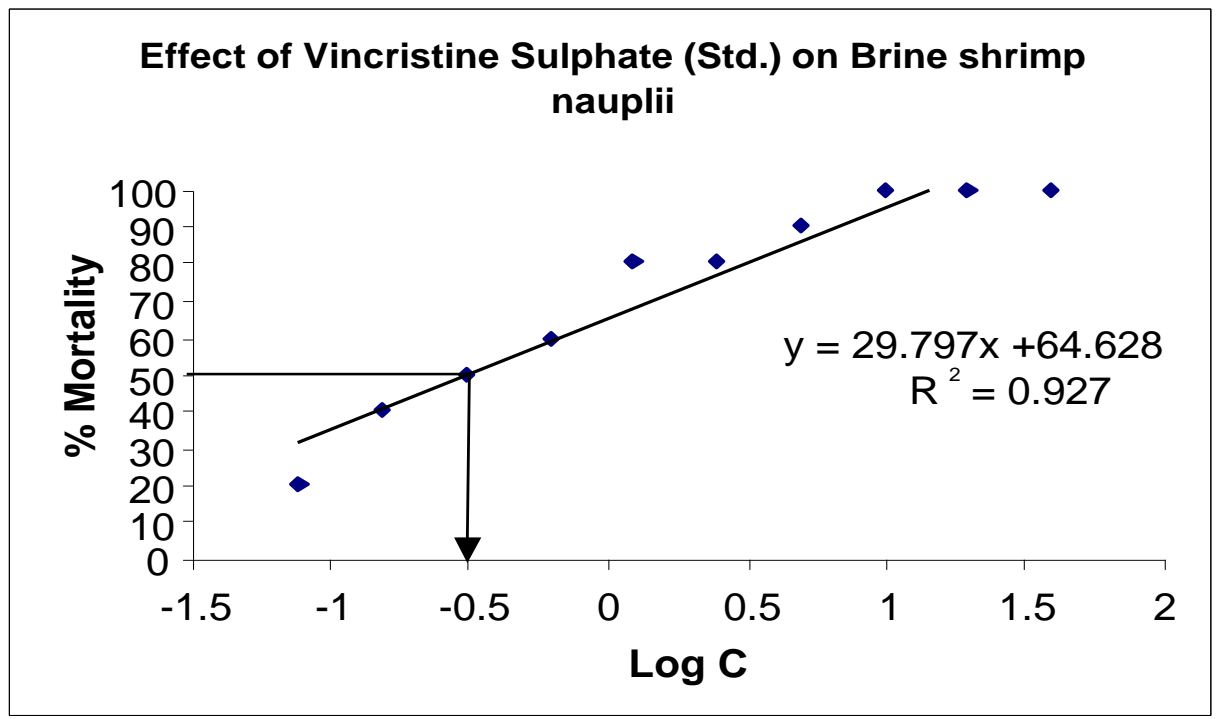

Fig. 1: Effect of Vincristine Sulphate on Brine Shrimp.

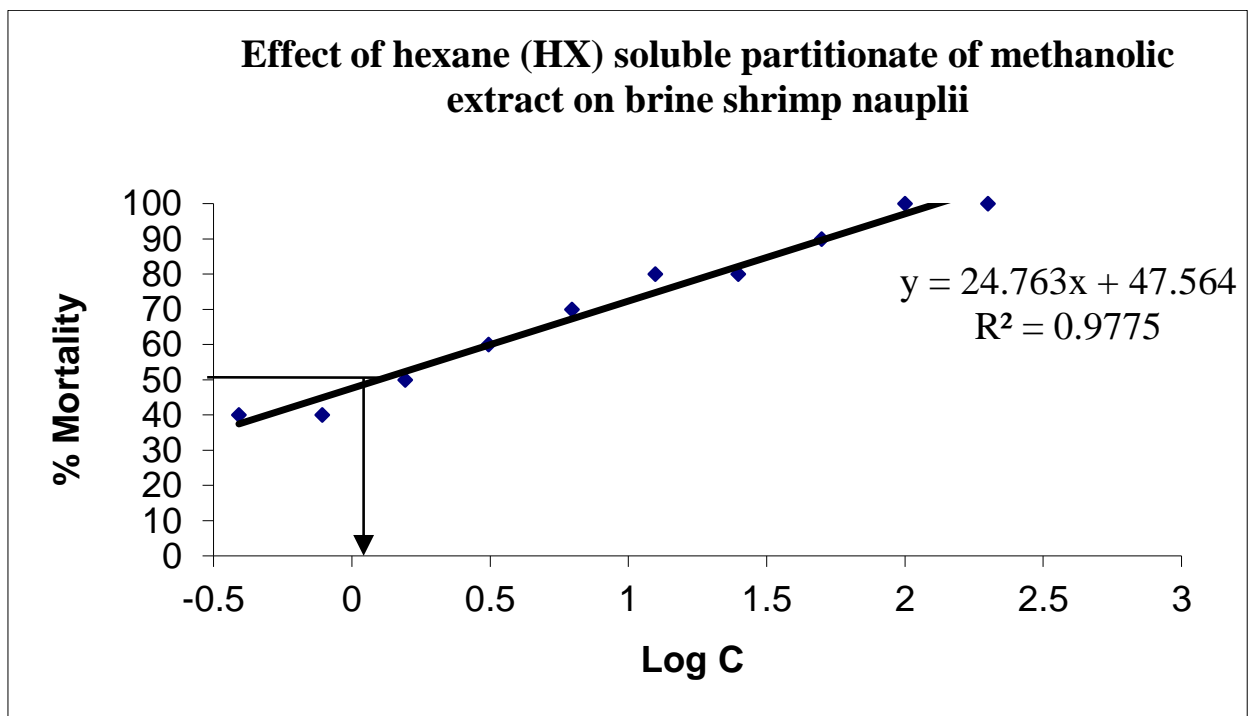

Fig. 2: Effect of Hexane (HX) Soluble Partitionate of Methanolic Extract on Brine Shrimp Nauplii. 


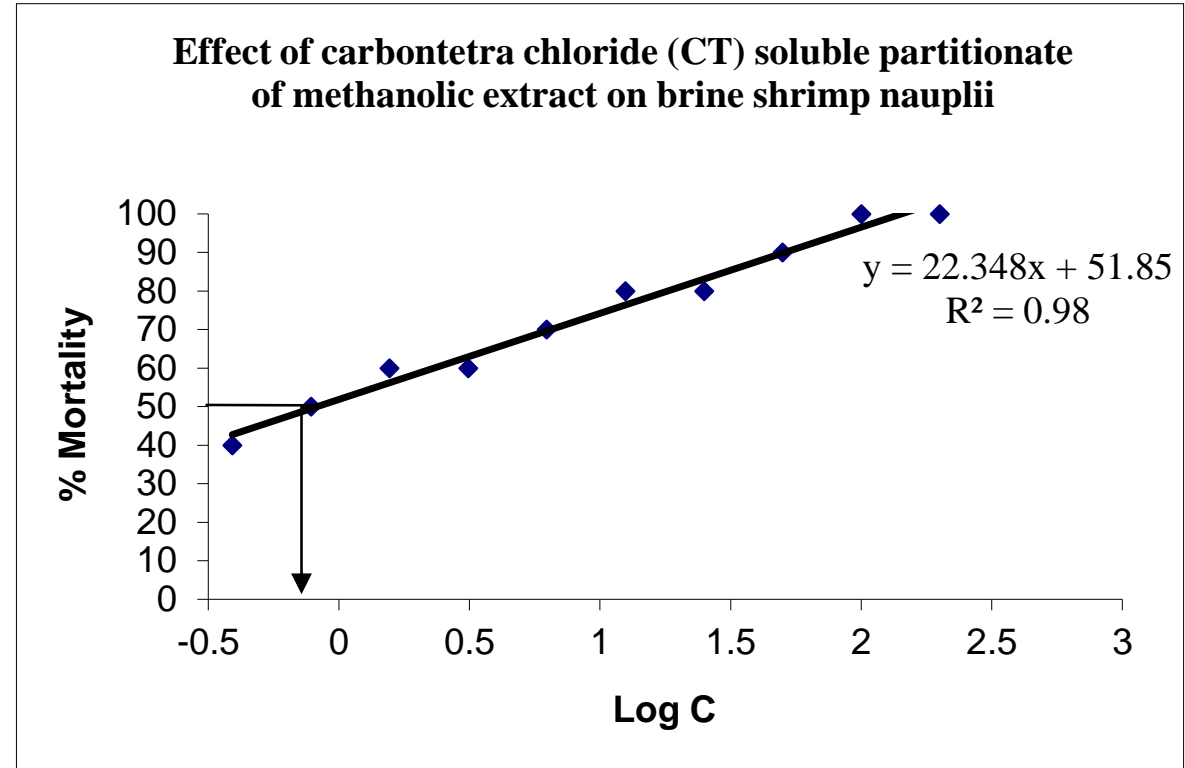

Fig. 3: Effect of Carbon Tetrachloride (CT) Soluble Partitionate of Methanolic Extract on Brine Shrimp Nauplii.

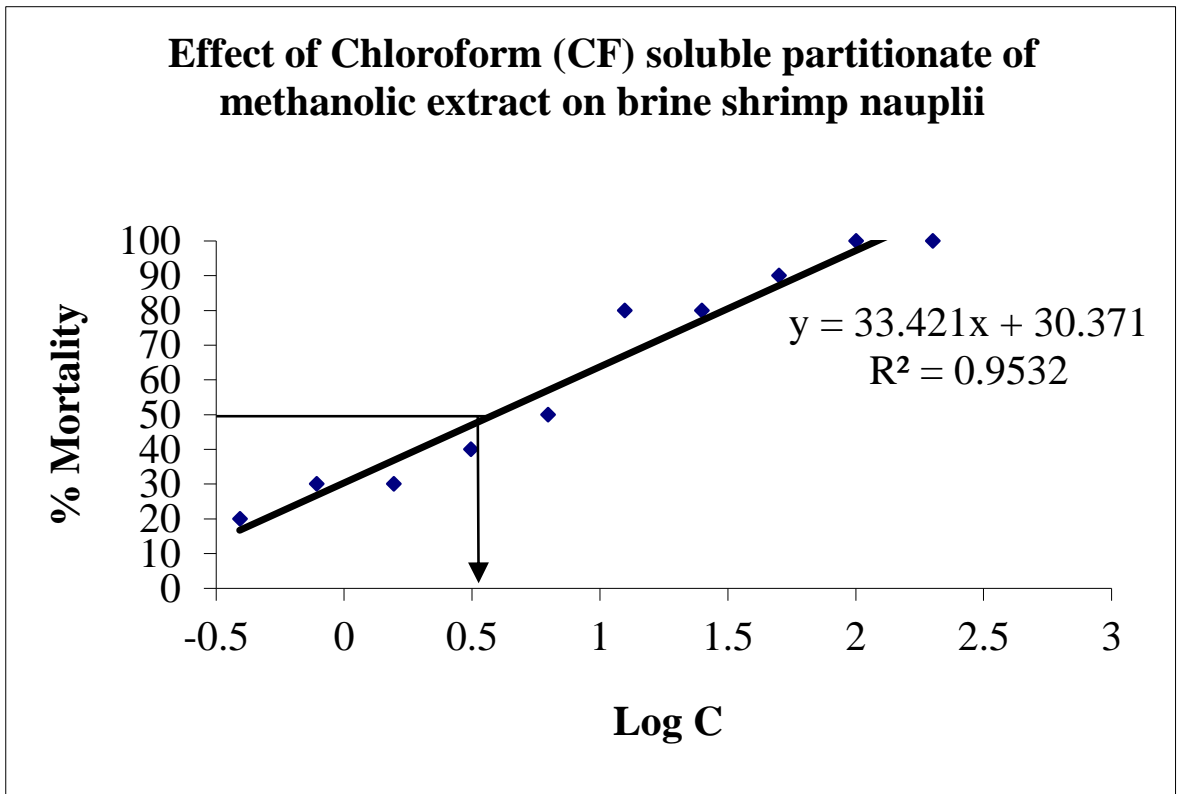

Fig. 4: Effect of Chloroform (CF) Soluble Partitionate of Methanolic Extract on Brine Shrimp Nauplii.

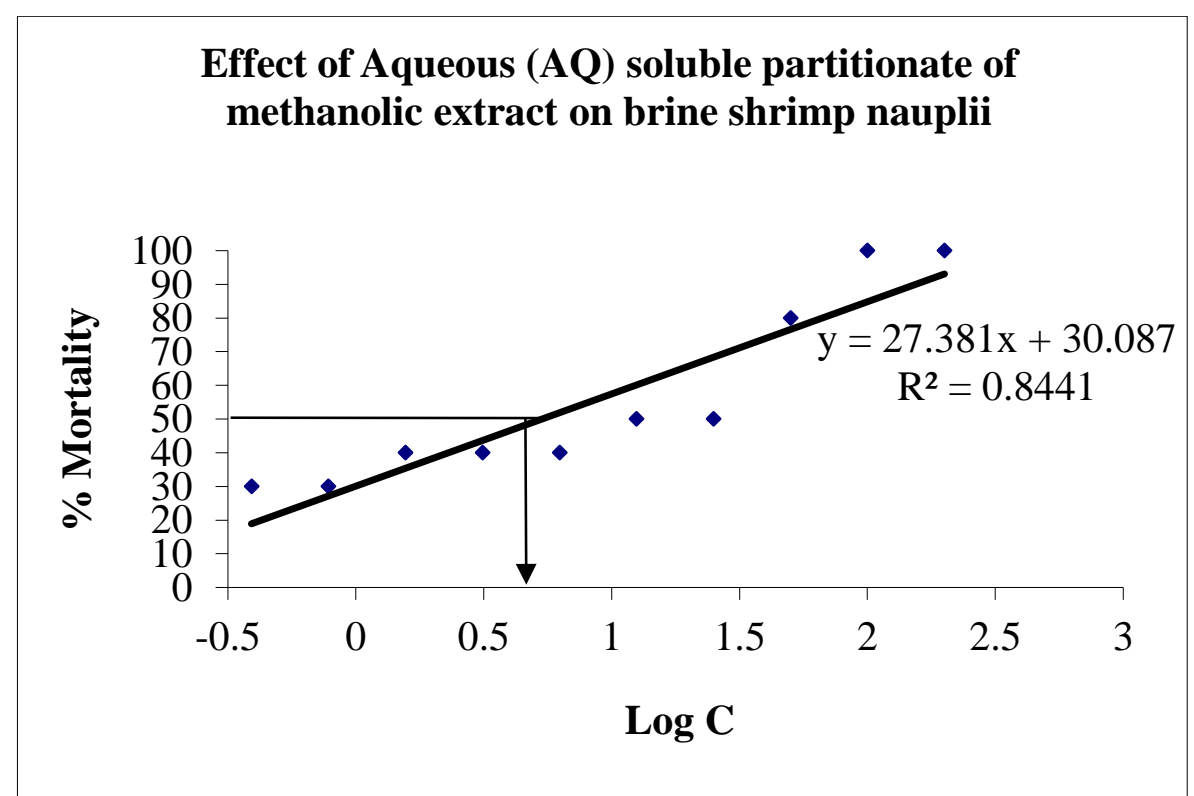

Fig. 5: Effect of Aqueous (AQ) Soluble Partitionate of Methanolic Extract on Brine Shrimp Nauplii. 


\section{Discussion}

Medicinal plants with antimicrobial properties are being increasingly reported from different parts of the world. The World Health Organization estimates that $80 \%$ of the world's population used plant extract or their active constituents as folk medicine in traditional therapies (Bhalodia and Shukla, 2011; Buwa and Staden, 2006). Our present study reveals that out of all the samples, chloroform \& carbon tetrachloride soluble partitionates of the methanolic extract appeared very potent in terms of both zones of inhibition \& spectrum of activity. Bioactivity-guided isolation can be carried out to separate there bioactive metabolites. Antimicrobial activity of test samples of Quisqualis indica is shown in table 1. This funding is supported by some previous reports done by the several workers (Valsaraj, et al., 1997; Srinivasan, et al., 2006; Samy and Ignacimuthu, 2000; Perumalsamy, et al., 1999; Parekh, et al., 2005). Quisqualis indica possessed tannin, alkaloids and steroids might account for this (Nitu, et al., 2011) and the antibacterial activity may be indicative of the presence of some metabolic toxins or broad-spectrum antibiotic compounds. In conclusion, the obtained results confirmed the presence of anti-microbial properties of Quisqualis indica, which supports the traditional use of this plant in various diseases caused by pathogenic microorganisms. Bioactivity guided isolation can be carried out to separate bioactive metabolites. Again, brine shrimp lethality bioassay (BSLB is used widely in the preliminary screening of the crude extracts to evaluate the toxicity towards brine shrimps, thus providing an indication of possible cytotoxic properties of the test materials (Meyer, et al., 1982). For evaluating cytotoxic activity of our present plant extract this method was chosen because this is easiest to conduct than any other methods and also said that the cytotoxic compounds generally exhibit significant activity in the BSLB; for all of this aspect this method become one of the recommended guidelines for the detection of antitumour compounds and pesticides due to its low cost (Manilal, et al., 2009). This bioassay also found to exhibit a positive relationship with the human solid tumor cell lines. It now becomes a proverb that if Correlation between cytotoxicity and activity against the brine shrimp nauplii using extracts have been established than cytotoxic effects of the plant extracts will enunciate for further cell line assay (Anderson, et al., 1991). Not only Bangladesh but also the country of the third world this method got the main consideration for conducting cytotoxic activity of plant extract. BSLB also hold the basement while conducting our present study to enunciate the cytotoxic activity of methanolic extract of Quisqualis indica. In comparison to positive control (vincristine sulfate), the cytotoxicity exhibited by carbon tetrachloride (CT) soluble partitionate of methanolic extract was promising. On the other hand, n-hexane \& chloroform soluble partitionates demonstrated moderate activity and aqueous soluble partitionate of methanolic extract showed poor activity. Present study data also showed a various rate of mortality at a different concentration as the report of Anderson et al. (Loux, et al., 1972) though there was no rate of mortality obtained. We want to conclude here with a massage that significant lethality (as LC50 value less than $100 \mathrm{ppm}$ or $\mu \mathrm{g} / \mathrm{ml}$ ) of the plant extract to brine shrimp is indicative of the presence of potent cytotoxic and probably insecticidal compounds which warrants further investigations.

\section{Conclusions}

In conclusion, the obtained results confirmed the presence of antimicrobial properties as well as the cytotoxic effect of Quisqualis indica, which supports the traditional use of this plant in various diseases caused by pathogenic microorganisms and act as a basis for anticancer drug screening from a natural source.

\section{Acknowledgement}

The authors would like to express their heartfelt gratitude, indebtedness, profound appreciation to Department of pharmacy and Applied Chemistry and Chemical Engineering of Noakhali Science and Technology University for their continuous support, untiring inspiration, scholastic supervision, constructive criticism, affectionate feeling and optimistic counseling throughout the project work. Authors are also grateful to Department of Microbiology, Noakhali Science and Technology University, Sonapur-3814, Noakhali, Bangladesh for their outmost support during the preparation of bacterial and fungal cell culture.

\section{Conflict of interest}

None declared

\section{Contribution statement}

Meer Hossain, Moin-Ul-Islam, and Md. Saddam Hussain was directly related to conducting this research work. Md. Abdur Rahman, Md. Shalahuddin Millat, Mirza Nusrat Sweety Contributed during data generation, manuscript preparation and Collection of the plant part. All of this authors are acknowledged about the publication of this research work.

\section{References}

[1] Ali NAA, Ju"lich WD, Kusnick C, Lindequist U. Screening of Yemeni medicinal plants for antibacterial and cytotoxic activities. Journal of Ethnopharmacology 2001; 74: 173-179. http://dx.doi.org/10.1016/S0378-8741(00)00364-0.

[2] Anderson JE, Goetz CM, McLaughlin JL, Suffness M. A blind comparison of simple bench-top bioassay and human tumour cell cytotoxicities as antitumor pre-screens. Phytochem Anal 1991; 2(3):107-111. http://dx.doi.org/10.1002/pca.2800020303.

[3] Balunas MJ, Kinghorn AD. Drug discovery from medicinal plants, Life $\quad \mathrm{Sci} \quad 2005 ; \quad 78: \quad 431 \quad-\quad 441$. http://dx.doi.org/10.1016/j.lfs.2005.09.012.

[4] Bauer J, Rojas R, Bustamante B. Antimicrobial activity of selected Peruvian medicinal plants. J Ethnopharmacol 2003; 88:199-204. http://dx.doi.org/10.1016/S0378-8741(03)00212-5.

[5] Bayer AW, Kirby WMM, Sherris JC, Turck M. Antibiotic susceptibility testing by a standardized single disc method. Am. J. Clin. Pathol 1966; 45:493-496.

[6] Beers MH, Berkow R. the Merck Manual of Diagnosis and Therapy. Whitehouse Station. NJ: Merck Research Laboratories 1999; $13: 161$

[7] Bhalodia NR and Shukla VJ. Antibacterial and antifungal activities from leaf extracts of Cassia fistula 1.: An ethnomedicinal plant. $J$ Adv Pharm Technol Res 2011; 2(2):104-109. http://dx.doi.org/10.4103/2231-4040.82956.

[8] Buwa LV, Staden JV. Antibacterial and antifungal activity of traditional medicinal plants used against venereal diseases in South Africa. Journal of Ethnopharmacology 2006; 103:139-142. http://dx.doi.org/10.1016/j.jep.2005.09.020

[9] Clement MV, Hirpara JL, Chamdhury SH, Pervaiz S. Chemopreventive agent resveratrol, a natural product derived from graps, triggers CD95 signaling-dependent apoptosis in human tumor cells. Blood 1998; 92:996-1002.

[10] Cozzi P, Mongelli N, Suarto A. Recent anticancer cytotoxic agents, Curr Med Chem Anticancer Agents 2004; 4:93-121. http://dx.doi.org/10.2174/1568011043482061.

[11] de Mesquita ML, de Paulab JE, Pessoac C, de Moraesc MO, CostaLotufoc LV, Grougnet R, Micheld S, ois Tillequind F, Espindolaa LS. Cytotoxic activity of Brazilian Cerrado plants used in traditional medicine against cancer cell lines. Journal of Ethnopharmacology 2009; 123:439-445. http://dx.doi.org/10.1016/j.jep.2009.03.018.

[12] De Padua LS, Bunyapraphatsara N, Lemmens RHMJ. PROSEA. Plant Resources of South-East Asia No.: Medicinal and Poisonous Plants 1999; 12:1. 
[13] Edeoga HO. Phytochemical constituents of some Nigerian medicinal plants. Afr J Biotech 2005; 4(7):685-688. http://dx.doi.org/10.5897/AJB2005.000-3127.

[14] FAO, Trade in Medicinal Plants, Economic and Social Department, Food and Agriculture Organization of the United Nations, Rome, Italy 2004

[15] Hossain MM, Ahamed SK, Dewan SMR, Hassan MM, Istiaq A, Islam MS, Moghal MMR. In vivo antipyretic, antiemetic, in vitro membrane stabilization, antimicrobial, and cytotoxic activities of different extracts from Spilanthes paniculata Leaves, Biological Research 2014; 47:45. http://dx.doi.org/10.1186/0717-6287-47-45.

[16] Huang L, Monroe E, et al., Introduction to Herbal Medicine 1998; 24.

[17] Khan A, Rahman M, Islam S. Antibacterial, Antifungal and Cytotoxic Activities of Tuberous Roots of Amorphophallus campanulatus. Turk J Biol 2007; 31:167-172.

[18] Kintzios SE and Barberaki MG. Plants that fight cancer. Boca Raton: CRC Press 2004. http://dx.doi.org/10.1201/9781420023718.

[19] Loux JJ, Deplama PD, and Yankel SL. Antipyretic testing of aspirin in rats. Toxicol. Appl. Pharmacol 1972; 22(4):672-675. http://dx.doi.org/10.1016/0041-008X(72)90295-5.

[20] Manilal A, Sujith S, Seghal KG, Selvin J, Shakir C. Cytotoxic potentials of red alga, laurencia brandenii collected from the Indian coast. Global J Pharmacol 2009; 3(2):90-94.

[21] Mercola DJ. E-natural health centre, Nutrition Consulting Company, Diet Consulting Company, Health naturally @ earthlink.net.Healthy Recipes with Food and Herbs 2006.

[22] Meyer BN, Ferrigni NR, Putnam JE, Jacobsen JB, Nicholsand DE, and Mclaughlin JL. Brine shrimp; a convenient general bioassay for active plant constituents. Planta medica 1982; 45:31-34. http://dx.doi.org/10.1055/s-2007-971236.

[23] Mia MMUK, Flora of Bangladesh (Combretaceae) 2006.

[24] Nitu S, Parveen K, Nikhilesh S, and Reena D. Pharmacognostic and phytochemical study of leaves of Quisqualis indica Linn. IJRPS 2011; 1(1):88-99.

[25] Parekh J, Jadeja S, Chanda S: Efficacy of Aqueous and Methanol Extracts of Some Medicinal Plants for Potential Antibacterial Activity. Turkish Journal of Biology 2005; 29:203-210.

[26] Perumalsamy R, Ignacimuthu S, Raja DP. Preliminary screening of ethnomedicinal plants from India. Journal of Ethnopharmacology 1999; 66:235-40. http://dx.doi.org/10.1016/S0378-8741(99)00038$\underline{0}$.

[27] Rahman M, Khatun A, Khan1 S, Hossain F, Khan AA. Phytochemical, cytotoxic and antibacterial activity of two medicinal plants of Bangladesh. Newsletter 2014; 1:3-10.

[28] Rao SR, Ravishankar GA. Plant cell cultures: Chemical factories of secondary metabolites. Biotechnol Adv 2002; 20(2):101-53. http://dx.doi.org/10.1016/S0734-9750(02)00007-1.

[29] Runyoro D, Matee M, Olipa N, Joseph C, Mbwambo H. Screening of Tanzanian medicinal plants for anti-Candida activity. BMC Complement Altern Med 2006; 6:11. http://dx.doi.org/10.1186/1472-6882-6-11.

[30] Samy RP, Ignacimuthu S. Antibacterial activity of some folklore medicinal plants used by tribals in Western Ghats of India. Journal of Ethnopharmacology 2000; 69:63-71. http://dx.doi.org/10.1016/S0378-8741(98)00156-1.

[31] Shahidi BH. Evaluation of antimicrobial properties of Iranian medicinal plants against Micrococcus luteus, Serratia marcescens, Klebsiella pneumonia and Bordetella bronchoseptica. Asian J Plant Sci 2004; 3:82-6, http://dx.doi.org/10.3923/ajps.2004.82.86.

[32] Srinivasan D, Nathan S, Suresh T, Lakshmanaperumalsamy P. Antimicrobial activity of certain Indian medicinal plants used in folkloric medicine. Journal of Ethnopharmacology 2001; 74:217-20. http://dx.doi.org/10.1016/S0378-8741(00)00345-7.

[33] Valsaraj R, Pushpangadan P, Smitt UW, Adsersen A, Nyman U. Antimicrobial screening of selected medicinal plants from India. Journal of Ethnopharmacology 1997; 58:75-83. http://dx.doi.org/10.1016/S0378-8741(97)00085-8.

[34] VanWagenen BC, Larsen R, Cardellina JH, Randazzo D, Lider $\mathrm{ZC}$, Swithenbank C. Ulosantoin, a potent insecticide from the sponge Ulosa ruetzleri. J. Org.Chem 1993; 58: 335-337. http://dx.doi.org/10.1021/jo00054a013.

[35] Welsh SL. Flora Societensis: A summary revision of the flowering plants of the Society Islands. E.P.S. Inc., Orem, Utah 1998; 64. 